probably due to delivering quickly those who are in danger. This is not always the best answer in the smallest. With them also there is the constant difficulty of deciding whether a birth should be classified as still or live. The use of perinatal rates by birth weight would overcome this difficulty statistically if not clinically.

Salvaging of high-risk infants-The DHSS have recently suggested extending this concept and recommended the establishment of regional superintensive baby care units so that even the smallest of preterm infants can be given superintensive care. The objective is to reduce neonatal deaths and future handicap. The follow-up of the very small survivors of those units already in existence, however, suggests a handicap rate of $7-18^{\circ}{ }_{0},{ }^{7}$ so that their exact position in relation to the overall reduction of handicap is being questioned. ${ }^{*}$

Prevention of spontaneous preterm delivery-Davies, ${ }^{7}$ when pointing out that this was the obvious answer, noted that the prematurity for England and Wales was not falling. There has been a disproportionate fall in the number of very small $(1000 \mathrm{~g}$ or less) live births, however, which has been followed in Sheffield by an actual fall in the prematurity rate from $7 \cdot 30^{\circ}{ }_{0}$ to $5 \cdot 96^{\circ}{ }_{0}$ from 1970 to 1975 . It seems likely, therefore, that this may be about to occur also in England and Wales. With the fall in the total birth rate there should be adequate facilities to provide first-rate obstetric hygiene and antenatal care to the people who need it most. Spontaneous preterm delivery is one of the hazards of social classes IV and V, so it is towards them that the major effort must be made. It will also be necessary by education (and perhaps payments like the French ${ }^{9}$ ) to convince these social groups that the facilities are worth using to the full. Fortunately obstetric interest in the prevention of preterm delivery is already lively, ${ }^{10-13}$ and it is to be hoped that this will increase.

Finally, since 1963 when figures for births of $1000 \mathrm{~g}$ or less were first recorded the neonatal mortality rate for this group in England and Wales has fallen from $85 \cdot 12^{\circ}{ }_{0}$ to $77 \cdot 3^{\circ}$, with an average of $80.95^{\circ}$ or for the years $1966-75$. For the same 10-year period infants of this weight group born and cared for in University College Hospital, London, showed an $80 \%$ mortality rate $^{6}$ - virtually the same as the national figure. It really still has to be proved that on a community basis superintensive care can improve survival rates.

\section{References}

${ }^{1}$ Gordon, R R, British Medical fournal, 1977, 1, 1313.

${ }^{2}$ Gordon, R R, British Medical fournal, 1977. In press.

${ }^{3}$ Committee on Child Health Services, Fit for the Future, vol 2, p 82, Cmnd 6684. London, HMSO, 1976.

4 Alberman, Eva, Health Trends, 1974, 6, 14.

5 Department of Health and Social Security, HC (76) 40

${ }^{6}$ Stewart, Ann L, et al, Archives of Disease in Childhood, 1976, 52, 97.

' Davies, Pamela, Archives of Disease in Childhood, 1976, 51, 817.

${ }^{8}$ Crawford, J S, and Wood, B S B, Lancet, 1977, 1, 899.

${ }^{9}$ Alberman, Eva, Morris, J M, and Pharoah, P O D, Lancet, 1977, 2, 393.

British Medical fournal, 1977, 1, 1118.

1 Weekes, A R L, Menzies, D N, and West, C R, British Medical fournal, $1977,1,16$.

${ }_{12}$ McNab, Margaret B, British Medical fournal, 1976, 2, 1201.

${ }^{13}$ Hunter, J, and Davies, J, British Medical fournal, 1976, 2, 1197.

(Accepted 9 September 1977)

\title{
Declaration of Hawaii
}

\section{Declaration adopted unanimously by the General Assembly of the World Psychiatric Association at the Sixth World Congress of Psychiatry, 1977}

British Medical fournal, 1977, 2, 1204-1205

Ever since the dawn of culture ethics has been an essential part of the healing art. Conflicting loyalties for physicians in contemporary society, the delicate nature of the therapist-patient relationship, and the possibility of abuses of psychiatric concepts, knowledge, and technology in actions contrary to the laws of humanity all make high ethical standards more necessary than ever for those practising the art and science of psychiatry.

As a practitioner of medicine and a member of society, the psychiatrist has to consider the ethical implications specific to psychiatry as well as the ethical demands on all physicians and the societal duties of every man and woman.

A keen conscience and personal judgment is essential for ethical behaviour. Nevertheless, to clarify the profession's ethical implications and to guide individual psychiatrists and help form their consciences, written rules are needed.

Therefore, the General Assembly of the World Psychiatric Association has laid down the following ethical guidelines for psychiatrists all over the world.

(1) The aim of psychiatry is to promote health and personal autonomy and growth. To the best of his or her ability, consistent with accepted scientific and ethical principles, the psychiatrist shall serve the best interests of the patient and be also concerned for the common good and a just allocation of health resources.

To fulfil these aims requires continuous research and continual education of health care personnel, patients, and the public.

(2) Every patient must be offered the best therapy available and be treated with the solicitude and respect due to the dignity of all human beings and to their autonomy over their own lives and health.

The psychiatrist is responsible for treatment given by the staff members and owes them qualified supervision and education. Whenever there is a need, or whenever a reasonable request is forthcoming from the patient, the psychiatrist should seek the help or the opinion of a more experienced colleague.

(3) A therapeutic relationship between patient and psychiatrist is founded on mutual agreement. It requires trust, confidentiality, openness, co-operation, and mutual responsibility. Such a relationship may not be possible to establish with some severely ill patients. In that case, as in the treatment of children, contact should be established with a person close to the patient and acceptable to him or her.

If and when a relationship is established for purposes other than therapeutic, such as in forensic psychiatry, its nature must be thoroughly explained to the person concerned.

(4) The psychiatrist should inform the patient of the nature of the condition, of the proposed diagnostic and therapeutic procedures, including possible alternatives, and of the prognosis. This information must be offered in a considerate way and the patient be given the opportunity to choose between appropriate and available methods.

(5) No procedure must be performed or treatment given against or independent of a patient's own will, unless the patient 
lacks capacity to express his or her own wishes or, owing to psychiatric illness, cannot see what is in his or her best interest or, for the same reason, is a severe threat to others.

In these cases compulsory treatment may or should be given, provided that it is done in the patient's best interests and over a reasonable period of time, a retroactive informed consent can be presumed, and, whenever possible, consent has been obtained from someone close to the patient.

(6) As soon as the above conditions for compulsory treatment no longer apply the patient must be released, unless he or she voluntarily consents to further treatment.

Whenever there is compulsory treatment or detention there must be an independent and neutral body of appeal for regular inquiry into these cases. Every patient must be informed of its existence and be permitted to appeal to it, personally or through a representative, without interference by the hospital staff or by anyone else.

(7) The psychiatrist must never use the possibilities of the profession for maltreatment of individuals or groups, and should be concerned never to let inappropriate personal desires, feelings, or prejudices interfere with the treatment.

The psychiatrist must not participate in compulsory psychiatric treatment in the absence of psychiatric illness. If the patient or some third party demands actions contrary to scientific or ethical principles the psychiatrist must refuse to co-operate. When, for any reason, either the wishes or the best interests of the patient cannot be promoted he or she must be so informed.

(8) Whatever the psychiatrist has been told by the patient, or has noted during examination or treatment, must be kept confidential unless the patient releases the psychiatrist from professional secrecy, or else vital common values or the patient's best interest makes disclosure imperative. In these cases, however, the patient must be immediately informed of the breach of secrecy.

(9) To increase and propagate psychiatric knowledge and skill requires participation of the patients. Informed consent must, however, be obtained before presenting a patient to a class and, if possible, also when a case history is published, and all reasonable measures be taken to preserve the anonymity and to safeguard the personal reputation of the subject.

In clinical research, as in therapy, every subject must be offered the best available treatment. His or her participation must be voluntary, after full information has been given of the aims, procedures, risks, and inconveniences of the project, and there must always be a reasonable relationship between calculated risks or inconveniences and the benefit of the study.

For children and other patients who cannot themselves give informed consent this should be obtained from someone close to them.

(10) Every patient or research subject is free to withdraw for any reason at any time from any voluntary treatment and from any teaching or research programme in which he or she participates. This withdrawal, as well as any refusal to enter a programme, must never influence the psychiatrist's efforts to help the patient or subject.

The psychiatrist should stop all therapeutic, teaching, or research programmes that may evolve contrary to the principles of this Declaration.

\title{
Letter from . . . Chicago
}

\section{Tutamania}

\author{
GEORGE DUNEA
}

In the first year of the Carterian era the Good God Nebkheprure Tutankhamon, Living Horus, Son of the Sun, Strong Bull, Lord of the Two Kingdoms, and twelfth pharaoh of the eighteenth dynasty, visited the United States. Wearing the double crown with the uraeus, he set out from Thebes's LuxorKarnak International Airport in his new Amon-Ra Concorde, flew over the Red Land and the Great Blue Water, and arrived in the City of the White House with his entourage. The next day, at the zoological gardens, he paid his respects to thi crocodile Sebek, the lioness Sekhmet, the cow Hathor, the ibis Thoth, the vulture Nekhbet, and the cobra goddess Buto, but did not know what to make of the panda and the kangaroo.

During the next few months the Great God interviewed 800000 people. He was told that the hyena gods of unemploy-

Cook County Hospital, Chicago, Illinois 60612

GEORGE DUNEA, MB, FRCPED, attending physician ment and inflation were losing ground but had not yet been banished, that Babylonian and Chaldaean oil was expensive and running out, and that people were being exhorted to ride on camels or in communal vehicles rather than in their own chariots. He heard that most people had no regrets about the fall of the former dynasty, that they were unimpressed with Mr David Frost's exhumation, that the former Great God could not have his tapes back, and that the Watergate episode was now as forgotten as the Amarna period. He was not surprised to hear that earlier pharaohs and high priests had also illegally bugged and wiretapped the temples of Amon or Aton. But he found on the whole that the people were well pleased with the new dynasty, that respect for the new high priests was growing, and that the polls indicated a rising popularity of $\mathrm{Mr}$ Carter (the one in the Great White House, not the one who had dug him up from the Valley of the Kings in 1922).

The Living Horus heard much talk about law and order. In many States the death penalty was coming back, also fixed sentences and reduced parole time, and curbs on the release from mental institutions of potentially dangerous individuals acquitted of violent crimes by reason of insanity. The Supreme Court had ruled that capital punishment was a disproportionate penalty for rape-and that States were not compelled to pay for poor people's abortions unless the mother's life was in 